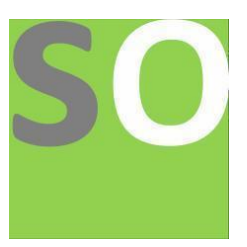

Article title: The Possible Responsiveness of FDI to Electric Power Consumption in Different Income Level Authors: Wondimu Sigo[1]

Affiliations: Institute of South-South Cooperation and Development, Peking University, Beijing, 5 Yiheyuan Rd, Haidian District, China, 100871[1]

Orcid ids: $0000-0002-7838-613 \times[1]$

Contact e-mail: wondimu1969@gmail.com

License information: This work has been published open access under Creative Commons Attribution License http://creativecommons.org/licenses/by/4.0/, which permits unrestricted use, distribution, and reproduction in any medium, provided the original work is properly cited. Conditions, terms of use and publishing policy can be found at https://www.scienceopen.com/.

Preprint statement: This article is a preprint and has not been peer-reviewed, under consideration and submitted to ScienceOpen Preprints for open peer review.

DOI: 10.14293/S2199-1006.1.SOR-.PPSZS7A.v1

Preprint first posted online: 24 August 2021

Keywords: Foreign Direct Investment, Electricity Power Consumption, Labor Force 


\title{
The Possible Responsiveness of FDI to Electric Power Consumption in Different Income Level
}

\author{
Author: Sigo T. Wondimu \\ Institute of South-South Cooperation and Development, Peking University, Beijing, 5 Yiheyuan Rd, \\ Haidian District, China, 100871 \\ Email: wondimu1969@gmail.com
}

\begin{abstract}
Modern energy in the form of electricity is vital for economic activities such as for getting clean water, and healthcare, for getting stable and effective lighting, heating, and cooking. However, in developing countries there is a huge shortage of electricity and big gaps in access, while access to electricity in developed countries almost reached a hundred percent. Hence, the purpose of this paper is to shows the possible responsiveness of FDI to electric power consumption in different income-level. Hence, this study aims to address questions, including how is the relationship between economic activities such as FDI and electricity consumption in different income-level. For motivating the research, 131 countries data have been collected from WDI and US-EIA from 1992 to 2016 and both quantitative and qualitative methods used.

The cross-country regression result shows that there exists an inverse-U shaped relationship between EPC and FDI net inflow because most high-income countries have a high level of EPC and therefore EPC becomes less important for them to attract FDI. But when we separate the total sample into two, EPC can significantly increase net FDI inflow for middle \& low-income countries because for these countries, especially for low-income countries, sufficient electricity supply is important for FDI inflow.
\end{abstract}

KEYWORDS: Foreign Direct Investment, Electricity Power Consumption, Labor Force 


\section{Introduction}

Economic growth is the most powerful instrument for decreasing poverty and improving the quality of human wellbeing by creating the resources required for human development. It is motivated by several factors, including process, product, and organizational improvements established on technological transformation. Hence, the economic growth in the past several years have shown big progress. It is well known that for this progress different sectors have contributed a lot. Among those sectors, foreign direct investment and energy played an important role in each country. To know the importance of energy in economic growth, it is essential; to begin with, the role of energy (Apergis \& Payne, 2011) in production because we can see that energy input is inducing production outputs very significantly. A more vibrant economy will have to use more energy to keep up with a higher level of production, as well as people's increasing demand for energy following the increased income level (Sadorsky, P., 2009). As income per capita of a country increases, demand for electric energy also increases to secure its people's well-being as well as to build a strong and productive economic foundation.

Reliance and demand for energy of countries have been growing due to increased innovations, industrialization, and globalization. The finding of Stern (2011) confirms that energy plays a matching role in labor and capital in the process of production. This means that with the use of energy in the production process, the efficiency of labor and capital grow together with the competitiveness of the nation's (Stern, 2011). Moreover, the economic development of a country depends upon its investment level. FDI is a catalyst for productivity enhancements and improved output levels in the host economy, permitting the local industry to reinvest its profits into the industry. On the other hand, investment, in turn, depends on the availability of infrastructure like electrical energy. Numerous researchers have tried to study the relationship between net inflows of FDI and energy consumption. The research has been concluded that as FDI allows for cheaper and easier access to capital, demand for energy increase with FDI inflows increase. This can, in turn, be used for expanding production, thus increasing energy demand and consumption (Mielnik, O. \& J. Goldemberg, 2002).

Modern energy facilities in the form of electricity are vital to human wellbeing and national economic growth. As a source of energy, electric power is transformed from the final form of energy using different technologies. Hence, as Apergis and Payne (2011) confirm it is mostly assumed that electricity has the widest means among other sources of energy and performs a critical role in the societal development of nations (Apergis \& Payne, 2011). There are different 
reasons why electricity service is important to increase living standards for human development. Access to modern energy is important for the delivery of clean water, hygiene, and healthcare, for delivery of consistent and effective lighting, heating, cooking, mechanical power, transport, internet, television, and telecommunications services (IEA, 2014). When electricity is accessible, food and drug can be kept in the refrigerator for an extended period, it will help more people to read and raises the adult learning rate so that the living situation will improve.

On the other hand, the deficiency of access to electricity can have substantial consequences on public health. This was confirmed by Hosking, Fletcher, and WHO (2011) that exposed the emissions of $\mathrm{CO} 2$ and hydrocarbons due to the burning of biomass frequently leads to sicknesses and death in several developing nations (Hosking, J., Mudu P., Dora C., \& WHO, 2011). In terms of number WHO (2018) report indicates that each year, due to household air pollution approximately 4 million people die using biomass fuels and kerosene that are cauterized as inefficient cooking practices (WHO, 2018). However, such an amount of premature death could be minimized by increasing access to electricity.

Electricity access refers to the percentage of individuals that have moderately basic, stable access to electricity (IEA, 2017) in a given region. The IEA electricity access explanation involves more than just supplying electricity to the household, which specifies the lowest threshold in the urban household per year is $500 \mathrm{kWh}$ and in the rural household per year is $250 \mathrm{kWh}$ (IEA, 2017). In general, at the global level, the population with access to electricity was growing over in the past twenty-five years that increased from $73.45 \%$ in 1993 to $88.85 \%$ in 2017. Hannah Ritchie and Max Roser (2018) have also found that upper-middle-income countries have access to electricity around 89-100 percent (Hannah R. \& Max R., 2018). In this context, the global population in terms of their income level that represents access to electricity at the household level from 1990 to 2017 is shown in figure 9.

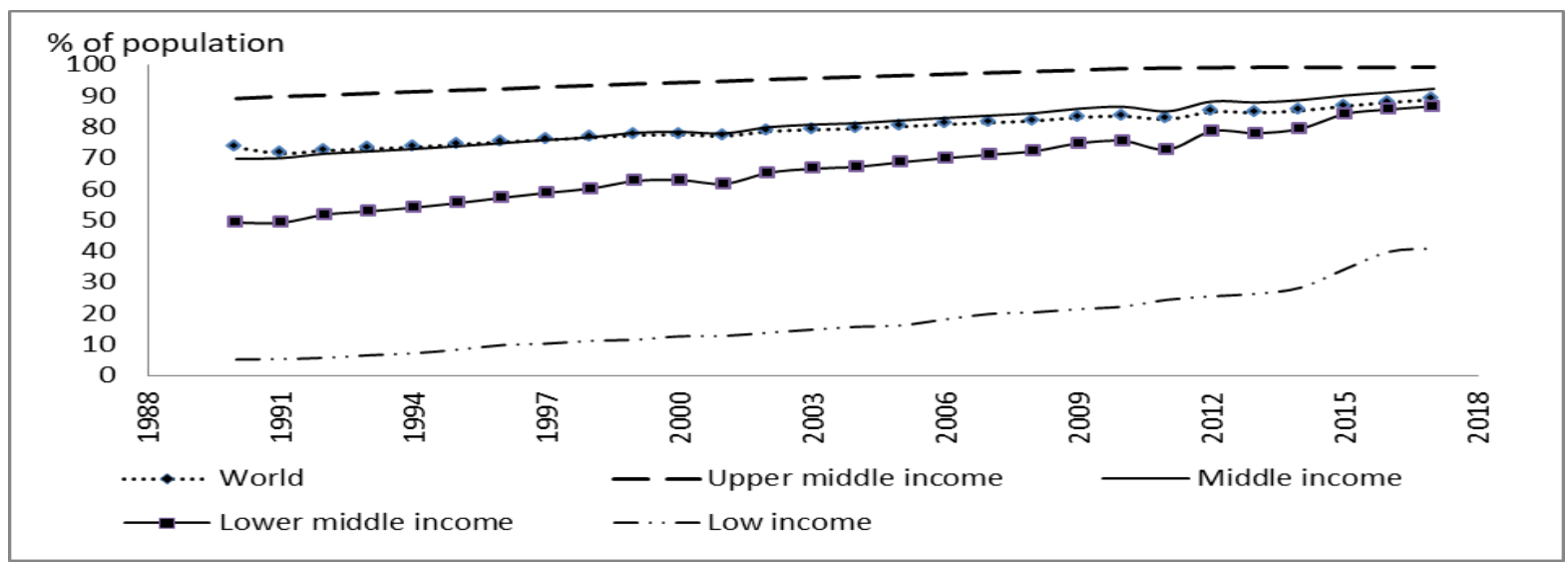


Data source: World Development Indicator

Figure 1: Access to electricity in terms of income in the global population

From figure 9, it can be understood that in terms of income level the global electricity access has grown. For instance, in 1990 access to electricity in the upper-middle-income and middleincome countries was $89.23 \%$ and $69.9 \%$ and increased to $99.37 \%$ and $92.36 \%$ in 2017 respectively. Similarly, lower middle income and low-income countries' access to electricity also increased from $49.3 \%$ and $5.2 \%$ in 1990 to $86.76 \%$ and $40.97 \%$ in 2017 respectively. However, the finding shows that access to electricity is not equal among the upper-middle, middle, lowermiddle, and low-income countries.

Moreover, when we examine in terms of geographic location as shown in figure 4.9 even if the access to electricity has grown, the distribution among the global population is not equal. For example, in 1990 access to electricity in Latin America \& Caribbean, East Asia \& Pacific, Middle East \& North Africa, and Sub-Saharan Africa were 85.5\%, 82.4\%, 85.8\%, and 23.5\%; and that increased in 2017 to $98.13 \%, 97.59 \%, 97.34 \%$, and $44.59 \%$ are respectively.

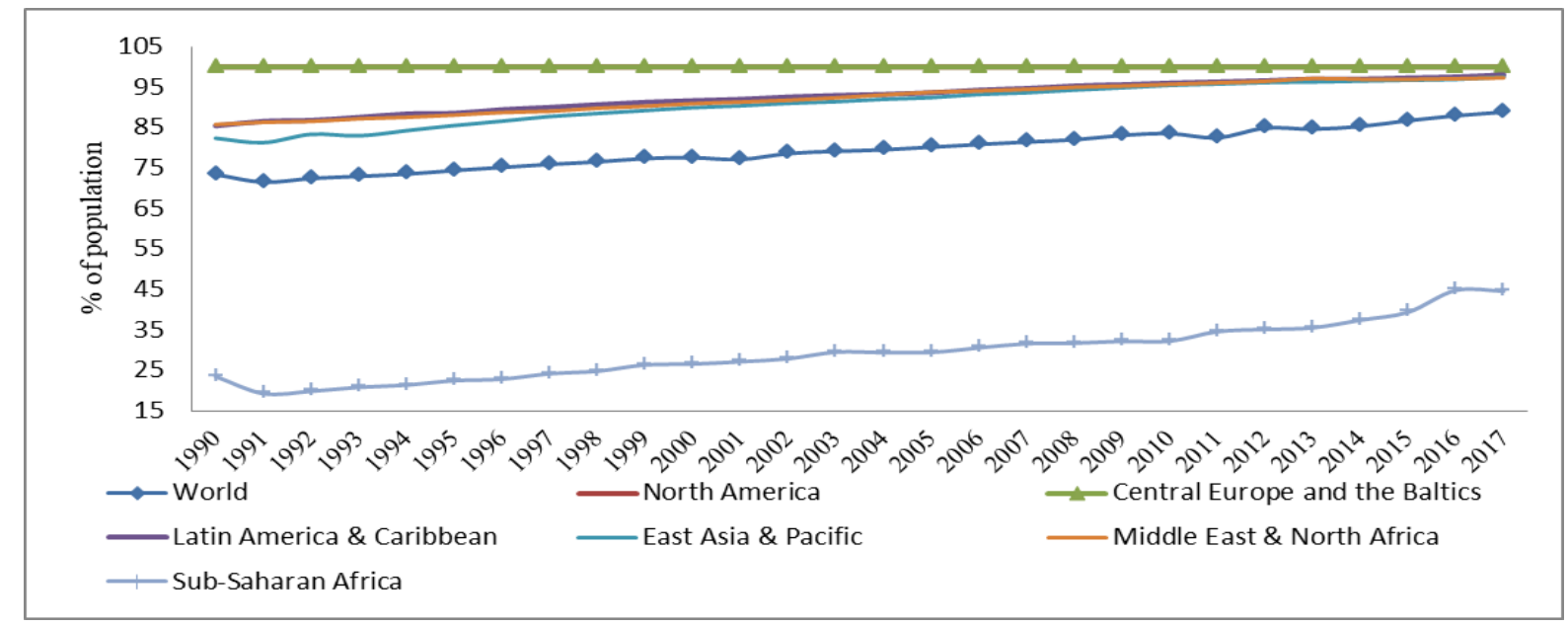

Data source: World Development Indicator

Figure 2: Access to electricity in terms of geography in the global population

Furthermore, the share of inhabitants with access to electricity from 1993 to 2017 as shown in figure 10 includes the rural, urban, and total population's access as the percentage of the population. As indicated in the figure rural population was below in terms of access to electricity out of the entire population. The implication is that electrification in most nations in rural inhabitants is less than in urban areas. For instance, access to electricity in 1993 rural, urban, and 
total were $59.8 \%, 93.1 \%$, and $72.9 \%$ which was increased to $78.64 \%, 97.4 \%$, and $88.85 \%$ in 2017 respectively.

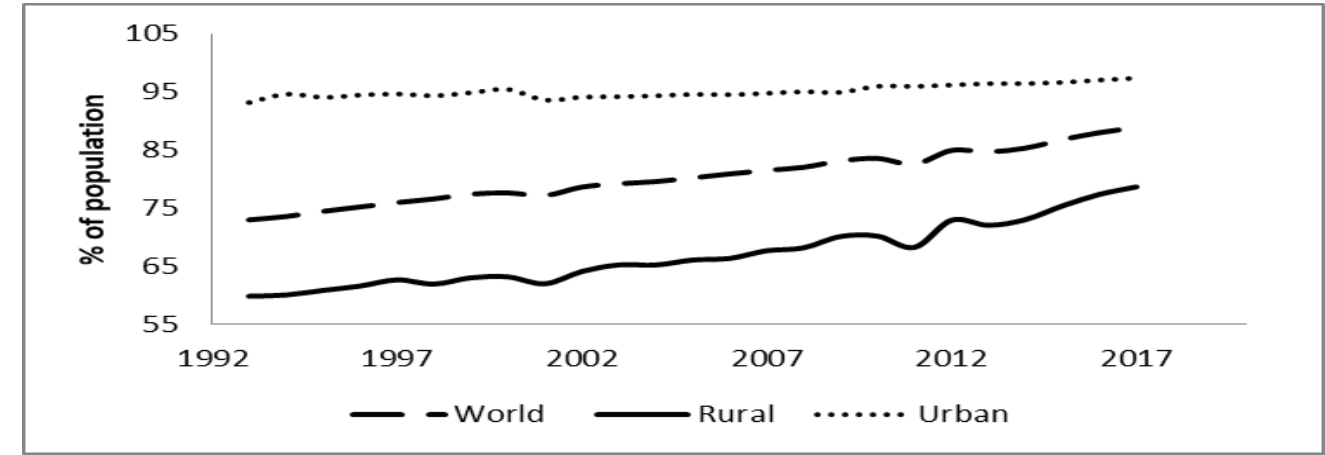

Data source: World Development Indicator

Figure 3: Access to electricity urban-rural world population

As per World Bank's (2016) report in Sub-Saharan Africa, it was even worse and nearly 45 percent of the people are living without electricity and most of those lacking electricity are in the rural areas (World Bank, 2016). The finding shows that in 1996 total access to electricity was $27.65 \%$, of which rural only $9.1 \%$ and urban $68.49 \%$. Access to electricity in this region didn't show significant improvement for the last 22 years, hence total access to electricity in 2017 reached 44.59 (\% of the population), of which in rural areas 22.6 (\%of rural population) and urban 78.96 (\% of the population), as shown in figure 11.

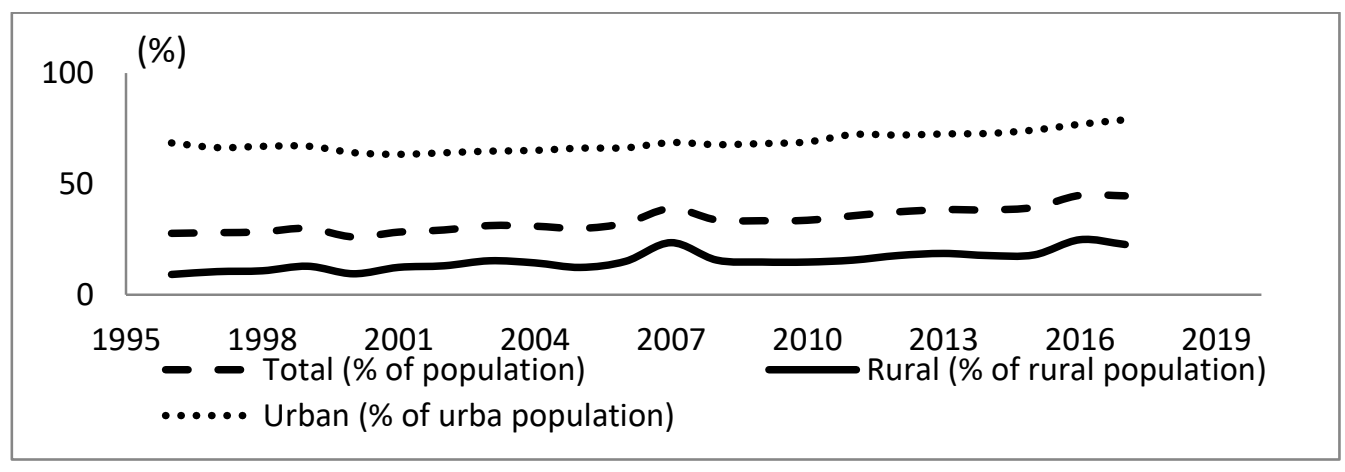

Data source: World Development Indicator

Figure 4: Sub-Saharan Africa access to electricity

In summary, the global access to electricity as per the three perspectives discussed above namely, in terms of income level, geographic location, and urban-rural inhabitants was not equally distributed around the globe. These findings confirmed by IEA (2017) report that about 1.1 billion people approximately $14 \%$ of the world's population yet not have access to electricity 
at home (IEA, 2017). Moreover, as it was projected by IEA (2017) in 2030 that 2.5 billion will still be depending on biomass for cooking and still around 1 billion people lack electricity access (IEA, 2017). Sovacool (2012) also confirmed that lack of access to energy services in addition to challenging human development; it inhibits the satisfaction of several human rights, such as improvement of society's living standard (Sovacool, B. K., 2012). Jumbe (2004) also found that as GDP shows a nation's development level, a nation's total and per-capita electricity consumption also reflects a measure of prosperity (Jumbe, C. B. L. , 2004).

For realizing access to electricity the world would need to increase investments. This means considerable development effects can be attained by investing in electricity supply and that would have downstream economic special effects in return. Therefore, electric power access and utilization do not only make life comfortable but also conserve time for production and accelerate economic growth. Hence, it is important to give special consideration for electric power access as it could assist to boost human development.

Moreover, as discussed above the world energy scheme is by its nature is very much complex. Electric power is an essential agent of socioeconomic development (J. Mawejje \& D.N. Mawejje, 2016), and growth in consumption of electric power is known as an indicator of national economic growth (Zhang, C., Zhou, K., Yang, S., \& Shao, Z., 2017).

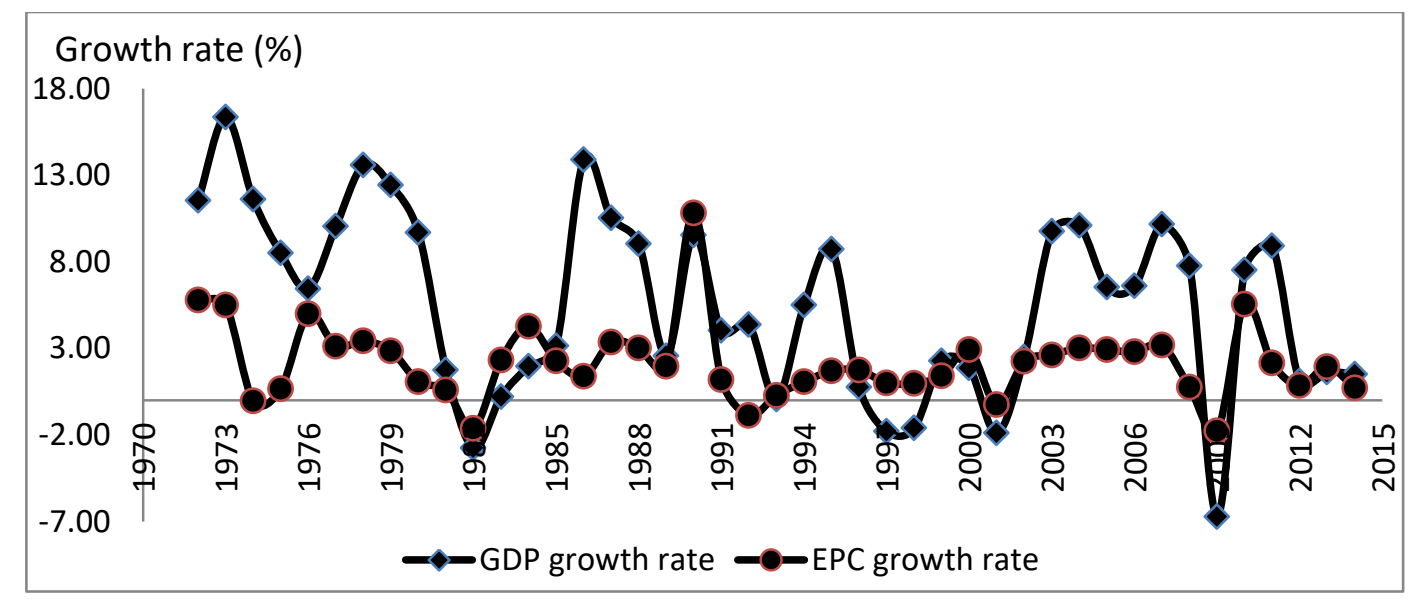

Data source: World Development Indicator

Figure 5: World growth rates of electricity consumption and GDP

Figure 13 above shows the growth rate trends in GDP and electricity consumption in the world. It shows that the world's economic growth rate kept a regular move with electricity consumption from 1971 to 2014 for more than four decades. The finding shows that electricity 
consumption per capita and GDP of the world was in 1972 was 1273.64KWh and 984.92US\$, and increased to $3130.71 \mathrm{KWh}$ and 10928.87US\$ in 2014 respectively. In other words when the economic growth rate increase, electricity consumption increases, and vice versa. This situation was seen in 1973 and 2008 when the oil crises and the world economic crises occurred respectively that both economic growth and electricity consumption rate were below zero.

However, in those periods the consumption of electricity indicated a huge difference in the world. For example, the major electricity consuming nations in 2017 are the People's Republic of China (25.9\%), the United States (17.5\%), India (5.4\%), Japan (4.5\%), the Russian Federation $(3.6 \%)$, Korea (2.4\%), Germany (2.4\%), Canada (2.4\%), Brazil (2.3\%), and France (2.0\%). These are the top-ten electricity consuming nation's that account for more than two-thirds of worldwide electricity consumption.

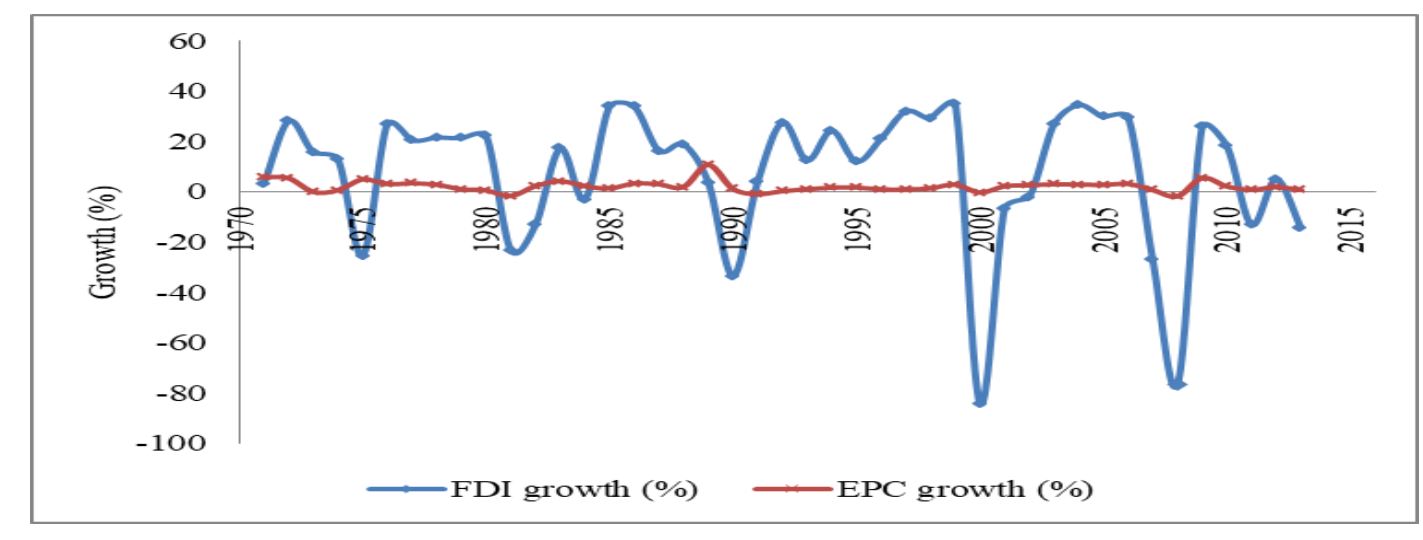

Data source: World Development Indicator

Figure 6: World growth rates of FDI and electricity consumption

On the other hand, as shown in figure 14 above, even if the ups and dawn of FDI net inflows and EPC per capita of the world are not the same, there is an indication that both went to each other. For instance, in 1972 when FDI growth was positive, 28.14\% and electric power consumption growth were also positive, 5.48\%, whereas in 2000 when FDI growth was negative $84.21 \%$ electric power consumption was also negative $0.27 \%$. Moreover, in 2005 when FDI growth improved and became positive $29.88 \%$ electric power consumption growth was also improved to $2.79 \%$, while in 2008 FDI growth became negative 76.61 and electric power consumption growth was also negative $1.77 \%$. Therefore, next, we found and discussed 
theoretically above about electric power consumption, and global economic activities such as FDI and GDP are also investigated empirically.

Therefore, the purpose of this paper is to investigate the possible responsiveness of FDI to electric power consumption in different income level at the global perspective. For motivating the research, 131 countries data have been collected from WDI and US-EIA from 1992 to 2016. The paper is structured as follows; Section-1 comprises an introduction that includes background and purpose of the paper, Section-2 deals with related works, Section-3 discuss methodology, Section-4 covers findings and discussions, Section-5 includes conclusion and recommendation.

\section{Related Work}

\subsection{Economic Growth and Energy Consumption}

Most of the literature shows that economic growth and energy consumption are very much related. This relationship between energy consumption and economic growth has been discovered widely. For example, Muhammad (2019) studied the relationship between economic growth, energy use, and CO2 emissions in emerging, MENA, and developed countries from 2001 to 2017. In his research, he found that economic growth has a positive and significant effect on energy consumption but no significant effect on $\mathrm{CO} 2$ emissions in emerging countries, while no significant effect on energy consumption but positive significant effect on $\mathrm{CO} 2$ emissions in MENA and developed countries. He also found that energy use has a positive significant effect on economic growth in emerging and developed countries, while no significant effect on economic growth in MENA countries. However, he found that in emerging, MENA, and all developed countries energy use has a positive and significant effect on $\mathrm{CO} 2$ emission (Muhammad, 2019).

Similarly, Ahmed, K., Bhattacharya, M., Shaikh, Z., Ramzan, and M., Ozturk, I., (2017), studied over 1985 to 2015 the relationship between economic growth, energy use, trade, and $\mathrm{CO} 2$ emission in Asian countries, and they found a positive relationship between energy use and $\mathrm{CO} 2$ emissions, unidirectional causality to $\mathrm{CO} 2$ emission and trade from economic growth for most of the countries, and they showed energy use as a key variable in the direction of environmental decline in the ASEAN countries (Ahamed et al., 2017).

Another study was done by Saidi and Hammami (2015) in 58 countries over the period 1990 on the relationship between energy use, $\mathrm{CO} 2$ emission, and economic growth examined and found a positive effect of energy consumption on economic growth and negative relationship between economic growth and CO2 emissions (Saidi \& Hammami, 2015). Similarly, Salahuddin 
and Gow (2014) studied from 1980-2012 the relationship between economic growth, energy consumption, $\mathrm{CO} 2$ emissions in Gulf countries, and empirical results found a positive significant relationship between $\mathrm{CO} 2$ emissions and energy consumption and also a positive significant relationship between economic growth and energy consumption both in the long run and shortrun (Salahuddin, M. \& Gow, J., 2014). The earlier studies Apergis and Payne (2010) found a positive relationship between economic growth and energy consumption (Apergis \& Payne, 2010).

\subsection{FDI and Energy Consumption}

Numerous researchers have tried to study the relationship between net inflows of FDI and energy consumption. The research has been concluded that as FDI allows for cheaper and easier access to capital, demand for energy increase with FDI inflows increase. This can, in turn, be used for expanding production, thus increasing energy demand and consumption (Mielnik, O. \& J. Goldemberg, 2002). The power and energy sector of Pakistan had received a higher amount of FDI than other sectors of the economy with trends of energy production and energy usage (Latief, R.; Lefen, L., 2019). Sun, P.; Wu, L. and Chen, S. (2011) studied 74 high income, middle income, and low-income countries energy consumption intensity and FDI on panel data of from 1985 to 2008 and they discovered that energy consumption intensity decreased marginally as FDI increased (Sun, P.; Wu, L.; Chen, S. , 2011). Moreover, Zhang and Xu (2016) found that energy consumption structures and FDI were advantageous in improving carbon productivity in resource-intensive sectors (Zhang, H.; Xu, K., 2016). Doytch and Narayan (2016) studied the environmental outcomes of FDI inflows and they claim that FDI is an essential driver of the increase in renewable energy consumption in upper-middle-income countries, while the effect in lower-middle-income countries is not as large (Doytch, N. \& S. Narayan, 2016).

\section{METHODOLOGY}

Regression is a common methodology for evaluating the statistical relationship between variables, which explains the relationship within an equation (Sarstedt, M., \& Mooi, E., 2014). To examine the relationship between the variables multiple linear regressions model is used because it is more suitable to explain the change of the dependent variable (Uyanık, G. K., \& Güler, N., 2013).

FDI flows to a particular country, is either demand driven by large market size of the host country, or supply-driven by the abundant labor supply and good infrastructure in the host country. The study uses GDP to represent the market size of the host country, the total labor 
force to represent the labor supply, and electricity consumption to represent the supply infrastructure.

In line with this theory, efforts are made include factors such as market represented by GDP per capita; infrastructure represented by electricity consumption per capita, labor represented by the labor force. We assume FDI flows are affected by market sizes such as the population and economic growth (GDP) measures in the host country. Similarly, infrastructure such as electricity, water, and road also affect FDI flows. Moreover, Labor force affects the flow of FDI in the form of labor supply and the cost of labor.

$$
\left.\mathrm{FDI}_{\mathrm{t}}=\mathrm{F} \text { (Market, Infrastructure, Labor) }\right)_{\mathrm{t}}
$$

Where:

$\mathrm{FDI}_{\mathrm{t}}$, Market $\mathrm{t}_{\mathrm{t}}$ Infrastructure $\mathrm{t}$, and Labor $_{\mathrm{t}}$ respectively represent foreign direct investment inflow, gross domestic product per capita, electricity per capita, and labor force.

Using this equation the finding in global perspective begins with a motivation question to evaluate the relationship between economic activities such as foreign direct investment and electricity consumption. Meaning the relationship between total FDI inflow (\$US), per capita GDP (\$US), per capita EPC (KWh), and labor force (in thousands) examined. In the analysis, panel data and FE are applied to evaluate the relationship between the dependent variable FDI and the independent variables within countries. The reason for using FE method is it will help us to control the individual characteristics of a country like the political or cultural situation that may have some effect on FDI and electricity per capita; and hence, this is the reason for the assumption of the error term (Oscar T. R., 2007). Second, we further check how renewable energy plays a role in the supply of electricity in different countries.

$$
\begin{gathered}
\mathbf{Y}=\boldsymbol{\beta}_{\mathrm{o}}+\boldsymbol{\beta}_{1} \mathbf{X}_{1}+\boldsymbol{\beta}_{2} \mathbf{X}_{2}+\cdots \boldsymbol{\beta}_{\mathrm{n}} \mathbf{X}_{\mathrm{n}}+\varepsilon \\
\mathbf{F D I}_{\mathrm{it}}=\boldsymbol{\beta}_{\mathrm{o}}+\boldsymbol{\beta}_{1} \mathbf{G D P}_{\mathrm{it}}+\boldsymbol{\beta}_{2} \text { Electricity }_{\mathrm{it}}+\boldsymbol{\beta}_{3} \text { Labor }_{\mathrm{it}}+\boldsymbol{\alpha}_{\mathrm{i}}+\text { year }_{\mathrm{t}}+\varepsilon_{\mathrm{it}}
\end{gathered}
$$

Since the data is a panel data, we also control country fixed effect and year fixed effect, which is a common time shock for all countries.

Where: 
$\mathrm{FDI}_{\mathrm{it}}, \mathrm{GDP}_{\mathrm{it}}$, Electricity $_{\mathrm{it}}$, and Labor ${ }_{\mathrm{it}}$, respectively represent - total foreign direct investment net inflow, per capita gross domestic product, per capita electricity power consumption, and total labor force, " $i$ " denotes country $i$ and " $t$ " denotes year " $t$ ", " $\alpha_{i}$ ", is the fixed effect of country $i$ that controls all characteristics of the country that is constant over the sample period, year ${ }_{t}$ control the yearly random shocks that are common to all countries in a year, $\varepsilon_{\mathrm{it}}$ the error.

Since our regression equation includes two endogenous variables, GDP and EPC, making it necessary to test the endogeneity if $E\left[\varepsilon \mid X_{1}, X_{2}, X_{n}\right]=0 v X_{j}$, then we say that we have explanatory exogenous variables. If, for some reason such as the omission of relevant variables, measurement errors, simultaneity, etc., $X_{j}$ is correlated with ", we say that $X_{j}$ is an endogenous explanatory variable (Burcu Eke, 2020). Hence, we will test endogeneity in the regression equation by predicting " $\mathrm{X}_{\mathrm{j}}$ " residual and lets $\mathrm{Xj}$ be "e". If p-value of the residual "e" small it indicates that there is an endogeneity problem that also shows the estimation of the model is not consistent. We also use Instrument Variable (IV) method to estimate the equation. Therefore, we will use the lag of GDP, EPC, and EPC2 as an instrument.

\section{xtivreg FDI LF (GDP EPC $=$ 1. GDP 1. EPC 1. EPC2), fe}

Lagged explanatory variables remain commonly used as instrumental variables (IVs) to address endogeneity concerns in empirical studies with observational data (Davidson \& Mackinnon, 1993). Finally to test the exogeneity we used the STATA command "dmexogxt" that gives the Davidson-Mackinnon test of exogeneity. Hence, as will be shown below, the regression analysis results confirm that the electricity supply is very important for countries, especially in low and middle-income countries, to attract FDI and drive economic growth.

\subsection{Data}

To choose the best suitable and appropriate materials as resources for the research topic numerous data had been collected from different sources. Most importantly world development indicators of World Bank, US-EIA, and IRENA data were utilized for the analysis. Hence, 
annual data from 1992 to 2016 for the 131 countries including "gross domestic product per capita (US\$)", "foreign direct investment inflow per capita (million US\$)", and "total labor force (thousands)" had been collected from WDI, which available online at http://www.worldbank.org. While electricity consumption in $\mathrm{kWh}$ data is found from US-EIA available online at https://www.eis.gov/beta/international/data/browse, then per capita EPC in kWh and renewable electricity consumption share was calculated.

Table 1 Descriptive statistics for whole 131countries

\begin{tabular}{lcllll}
\hline Variable & Obs & Mean & Std.Dev. & Min & Max \\
\hline FDI & 2947 & 10914.98 & 38275.91 & -29700 & 734000 \\
GDP & 2947 & 11245.08 & 16633.73 & 102.645 & 119000 \\
EPC & 2947 & 3416.56 & 4958.428 & .721 & 54439.96 \\
LF & 2947 & 23296.61 & 79765.68 & 137.5 & 786000 \\
& & & & \\
\hline
\end{tabular}

\section{Results and Discussion}

\subsection{Results}

Table 2 All country's data to test the possible responsiveness of FDI to electric power consumption (EPC)

\begin{tabular}{lrrr}
\hline Variables & $(1)$ & $(2)$ & $(3)$ \\
\hline GDP & $1.325^{* * *}$ & $1.287^{* * *}$ & $1.064^{* * *}$ \\
& $(0.092)$ & $(0.093)$ & $(0.089)$ \\
EPC & -0.250 & $3.415^{* * *}$ & $3.135^{* *}$ \\
& $(0.319)$ & $(1.107)$ & $(1.298)$ \\
EPC $^{2}$ & & $-5.46 \mathrm{e}-05^{* * *}$ & $-4.97 \mathrm{e}-05^{* * *}$ \\
& & $(1.58 \mathrm{e}-05)$ & $(1.82 \mathrm{e}-05)$ \\
LF & $0.994 * * *$ & $0.974^{* * *}$ & $0.938^{* * *}$ \\
& $(0.073)$ & $(0.073)$ & $(0.077)$ \\
Constant & $-25400^{* * *}$ & $-35900^{* * *}$ & $-31900^{* * *}$ \\
& $(3,474.48)$ & $(4605.02)$ & $(3566.16)$ \\
\hline
\end{tabular}

Note: $* * *$ represents significance at $1 \%$. 
Table 3 Separating the total sample into: high-income, and middle \& low-income countries.

\begin{tabular}{|c|c|c|c|c|c|}
\hline \multirow[b]{2}{*}{ Variables } & \multicolumn{3}{|c|}{ High-income } & \multicolumn{2}{|c|}{ Middle \&Low-income } \\
\hline & (1) & (2) & (3) & (4) & (5) \\
\hline \multirow[t]{2}{*}{ GDP } & $0.917 * * *$ & $0.889 * * *$ & $0.877 * * *$ & $1.188 * * *$ & $0.890 * * *$ \\
\hline & $(0.203)$ & $(0.204)$ & $(0.239)$ & $(0.186)$ & $(0.225)$ \\
\hline \multirow[t]{2}{*}{ EPC } & -0.424 & -3.180 & -3.326 & $8.090 * * *$ & $11.65^{* * *}$ \\
\hline & $(0.501)$ & $(2.360)$ & $(2.815)$ & $(0.815)$ & $(1.314)$ \\
\hline \multirow{2}{*}{$\mathrm{EPC}^{2}$} & & $-3.91 \mathrm{e}-05^{* * *}$ & $-7.88 \mathrm{e}-06$ & & \\
\hline & & $(3.27 e-05)$ & $(3.25 \mathrm{e}-05)$ & & \\
\hline \multirow{2}{*}{$\mathrm{LF}$} & $9.116 * * *$ & $9.111 * * *$ & $9.043 * * *$ & $0.777 * * *$ & $0.788 * * *$ \\
\hline & $(0.752)$ & $(0.752)$ & $(0.832)$ & $(0.034)$ & $(0.038)$ \\
\hline \multirow{2}{*}{ Constant } & $-113512 * * *$ & $-94675.89 * * *$ & $-92900 * * *$ & $-37300 * * *$ & $-42300 * * *$ \\
\hline & $(14,524.74)$ & $(21,432.01)$ & $(25,312.35)$ & $(2036.42)$ & $(2356.36)$ \\
\hline
\end{tabular}

Note: $* * *$ represents significance at $1 \%$.

\subsection{Discussion}

In table 4.3, column (1) reports the regression results for all countries that show the GDP size and total labor force of a country can significantly increase FDI inflow, while EPC has a negative but insignificant effect on FDI inflow. Since EPC is vital for production, it supposedly to increases FDI. We suspect that most high-income countries have a high level of EPC and therefore EPC becomes less important for them to attract FDI. We hence include the square term of EPC in the second column, and the result shows that there is an inverse- $U$ shaped relationship between EPC and FDI. That means as EPC increases, FDI increases first and then becomes flat or falls with a threshold value of $31,272=(3.415 /(2 * 0.0000546)) \mathrm{kWh}$. However, we also suspect an endogenous problem in variables (GDP and EPC), we test endogeneity in the regression equation by predicting the "e" residual. The small p-value of the residual "e" indicates that there is an endogeneity problem that also shows the estimation of the model is not consistent. So it can be concluded that there is an endogeneity bias in the OLS fixed estimates and it needs to instrument the variables (GDP, EPC, and $\mathrm{EPC}^{2}$ ) to make them exogenous see appendix C. Hence, we use the lag of GDP, EPC, and $\mathrm{EPC}^{2}$ as an instrument. Lagged explanatory variables remain commonly used as instrumental variables (IVs) to address 
endogeneity concerns in empirical studies with observational data (Davidson \& MacKinnon, 1993). To test the exogeneity we used the STATA command "dmexogxt" that gives the Davidson-Mackinnon test of exogeneity higher $\mathrm{p}$-value 0.5166 so that the model gives good results without endogeneity problem.

Therefore, according to column (3), the coefficient of lagged GDP 1.064 implies that one dollar increase in GDP per capita, the FDI inflow per capita will be increased by around 1.064 dollars one year later, ceteris paribus and statistically significant at $1 \%$. Similarly, the coefficient of lagged EPC 3.135, which suggests that one unit increase in EPC, FDI inflow also increased by 3.135 dollars one year later, ceteris paribus and statistically significant at 5\%. Finally, the coefficient of LF 0.974 implies that one unit increase in the total labor force, FDI net inflow per capita increases by about 0.974 dollars, ceteris paribus, and statistically significant at $1 \%$.

After doing the whole country panel data analysis to test the possible different responsiveness of FDI to EPC in different countries, we separate the total sample into two subsamples: highincome countries, and middle \& low-income countries as shown in table 4.4 above in column (1) the regression result of EPC for only high-income countries is not significant that implies EPC has no impacts on net FDI inflow in high-income countries. As electricity supply in high-income countries is abundant and is not a concern for consumption and production in their countries, EPC will not be a factor to be considered for foreign investors. Since most high-income countries have a high level of EPC and therefore EPC becomes less important for them to attract FDI. Then we include the square term of EPC in column (2), and the result shows that there is an inverse-U shaped relationship between EPC and FDI. That is, as EPC increases, FDI increases first and then becomes flat or falls. The threshold value is $37,947=(3.180 /(2 * 0.0000419)) \mathrm{kWh}$. 
However, since we already identified an endogenous problem in variables (GDP and EPC), it needs to instrument the variables (GDP, EPC, and $\mathrm{EPC}^{2}$ ) to make them exogenous and we use the lag of GDP, EPC, and $\mathrm{EPC}^{2}$ as an instrument and tested the exogeneity the result shows a higher p-value 0.2888 so that the model gives good results without endogeneity problem. Therefore, according to column (3), the coefficient of lagged GDP 0.877 implies that one dollar increase in GDP per capita, the FDI inflow per capita will be increased by around 0.877 dollars one year later, ceteris paribus and statistically significant at $1 \%$. Similarly, the coefficient of LF 9.043 implies that one unit increase in the total labor force, FDI net inflow per capita increases by about 9.043 dollars, ceteris paribus, and statistically significant at $1 \%$.

But for EPC, even after the lagged effect incorporated the result show statistically insignificant, because EPC is not a factor for high-income countries to attract investors. On the other hand, considering only middle and low-income countries the results are reversed. For these countries, especially for low-income countries, and abundant electricity supply is important for FDI inflow as shown in the table below. In table 4.4 column (4) \& (5) above we report the regressions to result for the middle and low-income countries that show EPC can significantly increase net FDI inflow. As we already identified an endogenous problem in variables (GDP and EPC), it needs to instrument the variables (GDP and EPC) to make them exogenous and we use the lag of GDP and EPC as an instrument and tested the exogeneity;

The result shows a higher p-value 0.9295 so that the model gives good results without endogeneity problem. Therefore, according to column (5), the coefficient of lagged GDP 0.890 implies that one dollar increase in GDP per capita, the FDI inflow per capita will be increased by around 0.890 dollars one year later, ceteris paribus and statistically significant at $1 \%$. Similarly, the coefficient of lagged EPC per capita is 11.65 and statistically significant at $1 \%$, which 
implies that one unit increase in EPC the net inflow FDI would increase by 11.65 units. Moreover, the coefficient of LF 0.788 implies that one unit increase in the total labor force, FDI net inflow per capita increases by about 0.788 dollars, ceteris paribus, and statistically significant at $1 \%$.

\section{Conclusion}

The finding of this research shows that as an essential input for production and indispensable good for consumption, electric power consumption is the driving force for economic activities. Especially, a stable and abundant supply of electric power is crucial to attracting foreign direct investment (FDI). The cross-country regression also shows that there exists an inverse-U shaped relationship between EPC and economic growth such as FDI net inflow in the whole 131 countries panel data. That is, as EPC in an economy increases, the net FDI increases first and then keeps rather stable or falls. Furthermore, by separating the sample into two, high income, and middle \& low-income countries, it is shown that the impact of EPC on FDI mainly comes from the middle \& low-income countries. The regression results show that EPC can significantly increase net FDI inflow for middle \& low-income countries but has no impact on net FDI inflow in high-income countries. As electricity supply in high-income countries is abundant and is not a concern for consumption and production in their countries, EPC will not be a factor to be considered for foreign investors. However, for middle \& low-income countries, the results are reversed. For these countries, especially for low-income countries, sufficient electricity supply is important for FDI inflow. Therefore, we conclude that to improve economic development it is essential to raise electricity supply. 


\section{Reference}

[1] AfDB. (2014). Annual Development Effectiveness Review 2014 - Towards Africa's transformation, Tunis. Retrieved from https://www.afdb.org/.../quality-assurance-results/developmenteffectiveness-reviews.

[2] AfDB, AU, \& NEPAD. (2011). Africa Energy Outlook 2040 -Study on Programme for Infrastructure Development in Africa (PIDA). Retrieved from https://www.afdb.org/fileadmin/uploads/afdb/Documents/Project-and-Operations/PIDA Study...

[3] Apergis \& Payne. (2011). A dynamic panel study of economic development and the electricity consumption-growth nexus. Energy Economics, 33(5), 770-781. https://doi.org/10.1016/j.eneco.2010.12.018.

[4] BP. (2017). Statistical Review of World Energy 2017. Retrieved fromhttps://www.bp.com/.../PDF/bpstatistical-review-of-world-energy-2017-full-report.pdf.

[5] Burcu Eke. (2020). Econometrics: Models with Endogenous Explanatory Variables. Retrieved from http://ocw.uc3m.es/economia/econometrics/lecture-notes-1/Topic6_logo.pdf.

[6] Davidson \& Mackinnon. (1993). Endogeneity concerns in empirical studies with observational data.

[7] Doytch, N. \& S. Narayan. (2016). Does FDI influence renewable energy consumption? An analysis of sectoral FDI impact on renewable and non-renewable industrial energy consumption. Energy Economics, vol. 54, p. 291-301.

[7] Hannah R. \& Max R. . (2018). Energy Production \& Changing Energy Sources. Published online at OurWorldInData.org. Retrieved from https://ourworldindata.org/energy-production-andchanging-energy-sources.

[8] Hosking, J., Mudu P., Dora C., \& WHO . (2011). Health in the green economy: Health co-benefits of climate change mitigation: the transport sector. Geneva, Switzerland: World Health Organization. Retrieved from https://apps.who.int/iris/bitstream/handle/1066. 
[9] IEA . (2014). Annual report online:

https://www.iea.org/publications/freepublications/.../2014_IEA_AnnualReport.pdf.

[10] IEA. (2017). Energy access outlook database. Retrieved from

https://www.iea.org/energyaccess/database/.

[11] IEA. (2017). Modern Energy for All. Retrieved from http://www.worldenergy utlook.org/resources/energy development/

[12] Jumbe, C. B. L. . (2004). Cointegration and causality between electricity consumption and GDP: empirical evidence from Malawi. Energy Economics, 26, 61-68. https://doi.org/10.1016/S01409883(03)00058-6.

[13] J. Mawejje \& D.N. Mawejje . (2016). Electricity consumption and sectoral output in Uganda: an empirical investigation. Journal of Economic Structures, vol. 5, no. 1, article no. 21, 2016. Retrieved from https://ideas.repec.org/a/spr/jecstr/v5y2016i1d10.1186.

[14] Latief, R.; Lefen, L. . (2019). Foreign direct investment in the power and energy sector, energy consumption, and economic growth: Empirical evidence from Pakistan. Sustainability 2019, 11, 192. [CrossRef].

[15] Mielnik, O. \& J. Goldemberg . (2002). Foreign direct investment and decoupling between 30 energy and gross domestic product in developing countries. Energy Policy, vol. 30, no. 2, p. 87-89.

[16] Oscar T. R. (2007). Panel Data Analysis Fixed and Random Effects using Stata (v. 4.2). Retrieved from https://www.princeton.edu/ otorres/Panel101.pdf.

[17] Pao. (2009). Forecast of electricity consumption and economic growth in Taiwan by state-space modeling. Energy, 34(11), 1779-1791. https://doi.org/10.1016/j.energy.2009.07.046.

[18] Sadorsky, P. (2009). Renewable energy consumption and income in emerging economies. Energy Policy, 37(10), 4021-4028. https://doi.org/10.1016/j.enpol.2009.05.003. 
[19] Sarstedt, M., \& Mooi, E. . (2014). Regression Analysis. In M. Sarstedt \& E. Mooi, A Concise Guide to Market Research (pp. 193-233). https://doi.org/10.1007/978-3-642-53965-7_7.

[20] Sean Ross . (2019). What Are the Best Measurements of Economic Growth? Retrieved from https://www.investopedia.com/ask/answers/032515/what-are-best-measurements-economicgrowth.asp.

[21] Sieminski, A. . (2013). International Energy Outlook 2013. 33. Retrieved from https://www.eia.gov/pressroom/presentations/sieminski_07252013.pdf.

[22] Sovacool, B. K. (2012). The political economy of energy poverty: A review of key challenges. Energy for Sustainable Development, 16(3), 272-282. https://doi.org/10.1016/j.esd.2012.05.006.

[23] Stern. (2011). The Role of Energy in Economic Growth. Crawford School Centre for Climate Economics \& Policy Paper No. 3.10. Retrieved from

[24] Sun, P.; Wu, L.; Chen, S. . (2011). On the nonlinear relationship between FDI and energy consumption intensity in an open economy: Analysis based on the framework of an environmental Kuznets curve. J. Financ. Econ. 2011, 8, 79-90.

[25] UNDP. (2004). Ghana "Liquefied petroleum gas (LPG) substitution for wood fuel in Ghana opportunities and challenges". Accra: 2004, UNDP Ghana.

[26] Uyanık, G. K., \& Güler, N. . (2013). A Study on Multiple Linear Regression Analysis. Procedia Social and Behavioral Sciences, 106, 234-240. https://doi.org/10.1016/j.sbspro.2013.12.027.

[27] WHO. (2009). Global health risks: Mortality and burden of disease attributable to selected major risks. Geneva, Switzerland: World Health Organization. Retrieved from https://www.who.int/healthinfo/global_burden_disease/GlobalHealthRisks_report_full.pdf.

[28] WHO. (2018). Household air pollution and health. Retrieved from https://www.who.int/newsroom/fact-sheets/detail/household-air-pollution-and-health. 
[29] World Bank. (2016). regulatory indicators for sustainable energy. Retrieved from http://documents.worldbank.org/curated/en/538181487106403375/pdf/112828-REVISEDPUBLIC-RISE-2016-Report.pdf.

[30] World Bank. (2016). World Bank Group Launches its 5th Economic Update for Ethiopia, December 6, 2016. Retrieved from https://www.worldbank.org/en/news/press-release/2016/12/...

[31] World Bank. (2018). The 6 Fastest-Growing Economies in Africa, 2018. Retrieved from https://www.africanexponent.com/post/the-6-fastest...

[32] Zhang, C., Zhou, K., Yang, S., \& Shao, Z. . (2017). On electricity consumption and economic growth in China. Renewable and Sustainable Energy Reviews, 76, 353-368. https://doi.org/10.1016/j.rser.2017.03.071.

[33] Zhang, H.; Xu, K. . (2016). Impact of environmental regulation and technical progress on industrial carbon productivity: An approach based on the proxy measure. Sustainability 2016, 8, 819. 


\section{Acknowledgments}

First and foremost, I would like to thank my God for His abundant love and for being my pillar of strength throughout my study. My sincere appreciation and respect to my supervisor, Professor WANG Min, for his continued support, guidance, and constructive comments. I feel very much lucky to have worked with him, thank you, professor. I would also like to thank the People's Republic of China for providing me a full scholarship to study at Peking University.

I am so much thankful to all my Professors at Peking University, Institute of South-South Cooperation, and Development (PKU-ISSCAD) for their priceless time and support during all the period of my study in China. I also thank all PKU-ISSCAD staff for their commitment and dedication to facilitating things easily especially Dr. Elisa, Mr. Edward Zhang, Mrs. Helen Hu, Ms. Kiki, Ms. Sylvie.

I also acknowledge in a very special way to my Chinese friends Mrs. Liu YU, Mr. YAN Xiangdong, Mr. WANG Yan Tao, Mrs. Xiao Wen Rong, Mrs. Liang Zhen, and Yiwen Wu, Mr. Cheo Chen. I also offer my thanks to my Ethiopian friends and families who helped with their support and by providing helpful comments and suggestions for my work especially Mr. Hailemelkot, Mrs. Taddis, Mr. Ayana, Mr. Getnet, Mr. Gosaye, Mrs. Buzunshe, Mr. Gezachew Z., Mr. Bisrate, Turku G., Alemayehu K., Mr. Asfa, Mrs. Tibebe Mrs. Tigest, Mr. Solomon T., and others for assisting me in various ways.

Last but not least a very special thank you goes to my family, my wife Meseret for covering my entire roles to the family, my daughter Elbetel and my son Kaleab for their understanding and encouragement while I am studying abroad and during research at home. 


\section{Originality Claims}

I hereby claim the thesis that I submitted is a product of my independent research work under the guidance of my supervisor. This paper does not contain the contents of published articles or written products by others without quotations. Those who made contributions to the completion of this paper were explicitly indicated in the thesis. I undertake all the legal responsibilities entailed in the claims. 